\title{
Pengaruh Produk, Testimoni Dan Store Atmosphere Terhadap Minat Beli Ulang Di Kafe Warunk Upnormal Gresik \\ Yohanes Dicky Yoeniargo ${ }^{1}$, Sutama Wisnu Dyatmika ${ }^{2}$ \\ Universitas PGRI Adi Buana Surabaya ${ }^{1,2}$ \\ Email : Yohanesdickyyon04@gmail.com
}

\begin{abstract}
ABSTRAK
Dalam menunjang usaha dalam meningkatkan pembelian pada warunk upnormal di gresik maka perlu dilakukan suatu penelitian mengetahui pengaruh Pengaruh Produk, Testimoni dan Store Atmosphere secara Terhadap Minat Beli Ulang di kafe Warunk Upnormal Gresik. jumlah ada 105 orang. Hasil penelitian diharapkan dapat digunakan oleh manajemen warunk upnormal dalam upaya meningkatkan pendapatn melalui peningkatan pembelian knsumen. Hasil pengujian diperoleh hasil bahwa Produk, Testimoni dan Store Atmosphere berpengaruh positif dan signifikan terhadap Minat Beli Ulang di Kafe Warunk Upnormal Gresik.
\end{abstract}

Kata kunci : Produk, Testimoni, Store Atmosphere dan minat beli ulang

\begin{abstract}
In supporting efforts to increase purchases in gresik warunk up, it is necessary to conduct a study to determine the effect of Product, Testimony and Store Atmosphere Influence on Repurchase Interest in the Wares Upnormal Gresik cafe. there are 105 people. The results of the study are expected to be used by upnormal warunk management in an effort to increase income through increased customer purchases. The test results obtained results that the Product, Testimony and Store Atmosphere have a positive and significant effect on Repurchase Interest in Wares Upnormal Gresik Cafe.
\end{abstract}

Keywords: Products, Testimonials, Store Atmosphere and repurchase interest. 


\section{Latar Belakang}

Saat ini persaingan bisnis semakin berkembang dengan membuat para pelaku usahha harus memutar otak agar usahanya tetap jalan dan bisa berkembang ditengah persaingan. Pelaku usaha yang tidak mempunyai inovasi dan ide-ide yang cemerlang dalam pengembangan usaha akan kalah bersaing dengan pelakuk usaha yang selalu melakukan inovasi dalam pengembangan usaha. Ada hal yg mempengaruhi konsumen dalam membeli antara lain produk, testimony dan store atmosphere.

Testimoni menjadi faktor penting sebagai bahan pertimbangan konsumen dalam menentukan minat beli . testimony dari konsumen yang telah melakukan pembelian sangat penting, karena oramg lain yang membaca testimony tersebu akan tertarik dan ikut melakukan pembelian.

Store atmosphere menjadi factor penting dalam meningkatkan minat beli ulang oleh konsumen. Suasana toko juga bisa membuat konsumen merasa lebih mempercayai pada produk yang dijual. Ratnasari dkk (2016:43) menggungkapkan apabila pelanggan merasa nyaman dengan suasana toko ditambah dengan kepuasan maka akan memungkinkan meningkatkan minat beli ulang. Jadi dapat disimpulkan bahwa store atmosphere merupakan rancangan lingkungan toko yang dirancang sedemikian rupa guna mempengaruhi minat beli ulang konsumen. Rancangan toko dibuat sedemikian rupa untuk menarik minat konsumen.

Warunk Upnormal gresik adalah salah satu usaha menyyuguhkan produk berbeda dengan produk lainnya. Banyak inovasi yang dilakukan oleh perintis dari warunk upnormal, sehingga warung upnormal dapat diterima dengan baik oleh konsumen. Warunk Upnormal menyediakan wifi, mainan seperti uno dan kartu juga interior desain yang unik. Kenyamanan tempat dan olahan mie instan yang unik sampai harga yang ditawarkan cukup terjangkau.

\section{Rumusan Masalah}

1. Apakah terdapat pengaruh produk (X1) terhadap minat beli ulang ?

2. Apakah terdapat pengaruh testimoni (X2) terhadap minat beli ulang?

3. Apakah terdapat pengaruh store stmosphere $(X 3)$ terhadap minat beli ulang?

4. Apakah terdapat pengaruh produk, testimoni dan store atmosphere secara simultan terhadap minat beli ulang?

\section{Landasan Teori}

Menurut Philip Kotler (2014:98) mendefinisikan produk sebagai bentuk sebuah produk yang biasanya ditawarkan kepada konsumen dalam memenuhi kebutuhan sehari-hari.

Adapun indicator produk adalah :

1. Rasa enak pada makanan

2. Penampilan menarik

3. menggugah selera

4. Tekstur dari makanan yang di sajikan

Adapun indikator testimoni yang digunakan :

a. Pesan dapat dipercaya

b. Sumber terpercaya

c. Citra positif

d. Testimoni berasal dari pelanggan

Adapun indicator store atmosphere :

1. Bagian Luar

2. Bagian dalam

3. Interior Pop Display

4. Store Layout 


\section{Kerangka Konseptual}

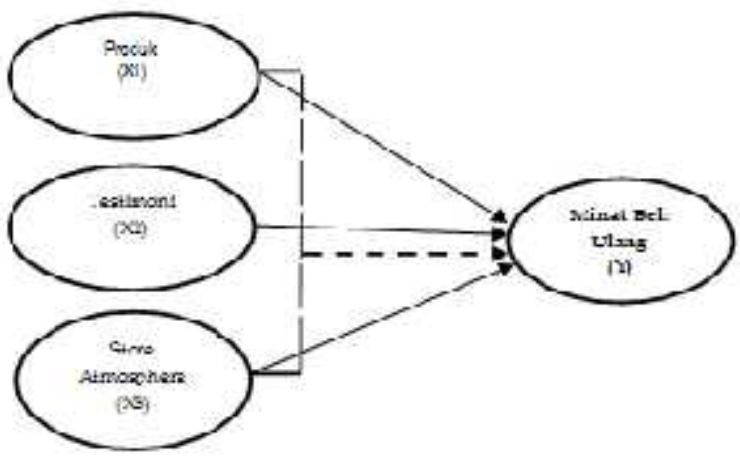

Gambar 1

Kerangka Konseptual

Hipotesis

$\mathrm{H}_{1}$ : Diduga terdapat pengaruh Produk secara parsial terhadap Minat Beli Ulang

$\mathrm{H}_{2}$ : Diduga terdapat pengaruh Testimoni secara parsial terhadap Minat Beli Ulang

$\mathrm{H}_{3}$ : Diduga terdapat pengaruh Store Atmosphere secara parsial terhadap Minat Beli Ulang

$\mathrm{H}_{4}$ : Diduga terdapat pengaruh Produk, Testimoni dan Store Atmosphere secara simultan terhadap Minat Beli Ulang

\section{Populasi dan Sampel}

Populasinya adalah seluruh pengunjung atau konsumen di Kafe Warunk Upnormal Gresik. Adapun sampel berjumlah 105 orang.

Teknik Pengumpulan data

Teknik pengumpulan data menggunakan kuisioner.

\section{Variable Penelitian}

a. Variable bebas $(x)$

- Produk (X1)

- Testimoni (X2)

- Store Atmosphere (X3) b. Variable terikat $(Y)$

- Minat Beli Ulang (Y).

\section{Analisis data dan hasil penelitian}

a. Uji validitas

Tabel 1

Hasil Uji Validitas

\begin{tabular}{|c|c|c|c|}
\hline $\begin{array}{c}\text { tem } \\
\text { Patanyan }\end{array}$ & $\begin{array}{l}\text { Corress } \\
\text { finm-Tota } \\
\text { corruston }\end{array}$ & Nia Krtat & Kobarangan \\
\hline \multicolumn{4}{|c|}{ Vanabel Produk (x)! } \\
\hline PRt_i & 0.917 & 0.8 & vase \\
\hline FM: & ग्8क् & 05 & Ward \\
\hline FK2_I & 09 & 03 & Vad \\
\hline Pr:2 & 285 & 0,3 & Vad \\
\hline FrSI & ग्वा? & 05 & Fisd \\
\hline FRS 2 & 091 & 0,3 & Vad \\
\hline PRA_I & 085 & 0,3 & vas \\
\hline $6 \pi 2_{2}$ & $0 \$ 02$ & 0,5 & Visto \\
\hline \multicolumn{4}{|c|}{ Variabel T sebingni $\left(C_{2}\right.$ ) } \\
\hline TH.t_t & 0,515 & 0,5 & vaido \\
\hline Tats2 & ग655 & 05 & Vad \\
\hline TM2 & $03 \%$ & 0,3 & $\mathrm{Vai}$ \\
\hline$T 1422$ & 2517 & 0,8 & vald \\
\hline TrSS & 0865 & $0 / 3$ & Va:d \\
\hline THS & ग822 & 03 & Vad \\
\hline $7 T_{2}=1$ & गध2 & 0,3 & Vad \\
\hline THA2 & 09 & 0,5 & Vaid \\
\hline \multicolumn{4}{|c|}{ 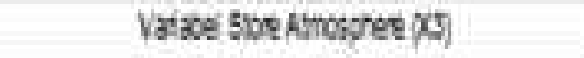 } \\
\hline 92 & 144 & di & Hit \\
\hline & DAF & gIt & TaN \\
\hline & DRE & 7, & TA \\
\hline & 14 & 1) & VIf \\
\hline & 194 & 98 & PIS \\
\hline 243 & 1941 & 93 & 12: \\
\hline mil & Plit & 97 & TIP \\
\hline A-12 & ify & 92 & 124 \\
\hline
\end{tabular}

Vatbe that ba ung

\begin{tabular}{|c|c|c|c|}
\hline Met & WW & 75 & W14 \\
\hline $7 E T 2$ & DKR & 05 & T3id \\
\hline TE2I & DWI & 03 & Tas \\
\hline 1822 & 754 & TI & Tith \\
\hline M6: & 695 & $6 j$ & $\sqrt{130}$ \\
\hline Meth & 087 & 05 & lad \\
\hline
\end{tabular}

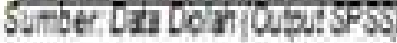

Keseluruhan item di anggap valid karena semua item pada pengujian didapat nilai sig $<0,05$. 
b. Uji Realibiltas

Tabel 2

Hasil Uji Reliabilitas

\begin{tabular}{|c|c|c|c|}
\hline 'Vanabe' & $\begin{array}{l}\text { Conbach's } \\
\text { Alona }\end{array}$ & $\begin{array}{l}\text { Nia } \\
\text { Kotis }\end{array}$ & Keterangan \\
\hline Proouk $\alpha_{1}$ & 0,974 & 0,60 & Feliabe: \\
\hline Testmon $\left.\chi_{a}\right]$ & 0,975 & 0,60 & Relabe' \\
\hline Store Atmosphere $\left(X_{i}\right)$ & 0,977 & 0,60 & Reliabe: \\
\hline Mtnat Beis Uang $(Y]$ & 0,967 & 0.60 & Reliabs: \\
\hline
\end{tabular}

Adapun hasil penelitian diperoleh nilai koefisien reliabilitas cronbach alpha pada variabel produk $=0,974$, variabel testimoni $=0,975$, variabel store atmosphere $=0,977$ dan variabel minat beli ulang $=r$ 0,967. Hal ini dinyatakan bahwa semua variabel reliabel, sehingga kuesioner yang dibuat sebagai bahan acuan untuk penelitian dapat diterima responden dengan baik dan layak untuk dilanjutkan sebagai instrument penelitian.

\section{Pengujian Asumsi klasik}

a. Uji normalitas

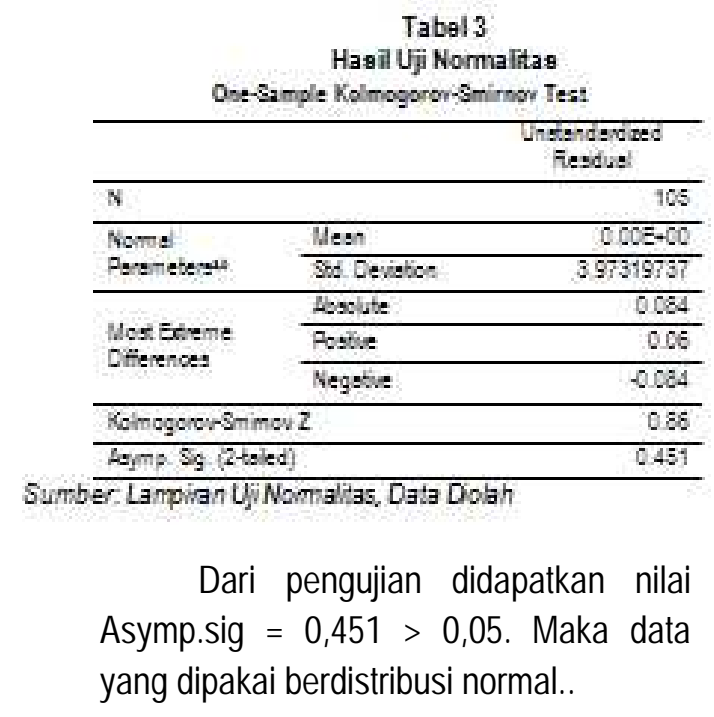

b. Uji Multikolinieritas

\begin{tabular}{|c|c|c|c|}
\hline \multicolumn{4}{|c|}{$\begin{array}{c}\text { Tabel } 4 \\
\text { Hasil Uji Multikolonieritas } \\
\text { Coeffcients' }\end{array}$} \\
\hline \multirow{2}{*}{ Mode } & & \multicolumn{2}{|c|}{ Colnesity Sratatica } \\
\hline & & Tolergnos & VF \\
\hline \multirow{3}{*}{1} & Produk (X1) & 248 & 4033 \\
\hline & Textinoni $\left(\mathrm{N}_{2}\right)$ & 253 & 3951 \\
\hline & Store Lenosphere (Xs) & 370 & 2700 \\
\hline
\end{tabular}

Dari hasil analisis menggunakan uji multikolinieritas diperoleh nilai VIF variabel produk sebesar 4,033, variabel testimoni sebesar 3,951 dan variabel store atmosphere sebesar 2,700. semua variabel mempunyai nilai VIF $<10$.

c. Uii Autokorelasi

\begin{tabular}{|c|c|c|}
\hline & $\begin{array}{l}\text { Hail Uf Autokorelasi } \\
\text { Moder Summarye }\end{array}$ & \\
\hline Moose & Duton-ivatson & \\
\hline$T$ & & $1.672^{2}$ \\
\hline
\end{tabular}

Dari pengujiana didapat nilai DW yang didapatkan sebesar 1,672 . NilaiDW berada diantara nilai 1,55 $<1,672<2,46$. maka dapat di simpulkan bebas dari uji autokorelasi..

d. Uji Heterokeditas

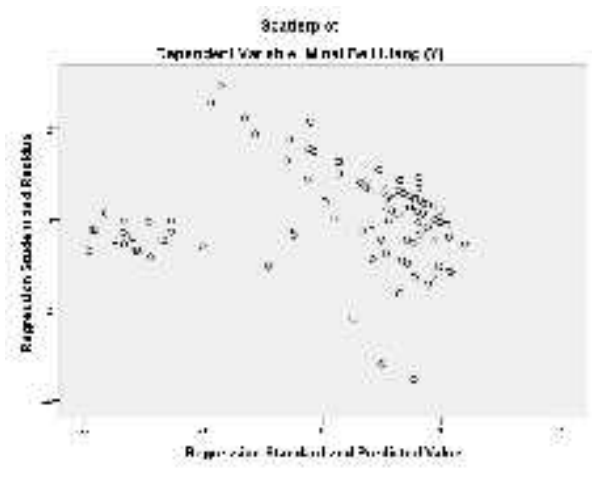


Analisis Regresi Linier berganda

Tabel 3

Tabel uji regresi linier berganda

Coefficients $x$

\begin{tabular}{|c|c|c|c|}
\hline \multirow{2}{*}{\multicolumn{2}{|c|}{ Model }} & \multicolumn{2}{|c|}{$\begin{array}{l}\text { Unstandardized } \\
\text { Coefficients }\end{array}$} \\
\hline & & B & Sid. Error \\
\hline \multirow{4}{*}{1} & (Constant) & 4.005 & 1.538 \\
\hline & Produk $\left[X_{1}\right]$ & 260 & .098 \\
\hline & Testimoni $\left\{X_{2}\right]$ & .196 & .091 \\
\hline & $\begin{array}{l}\text { Siore A tmosphere } \\
\text { (X3) }\end{array}$ & .175 & .078 \\
\hline
\end{tabular}

a. Dependent Variable: Mnat Beli Ulang $(Y]$

Sumber :Lampiran Analisis Regresi Linier Berganda

\section{Persamaan Garis Regresi}

Berikut ada persamaan regresinya :

$$
Y=4,065+0,260 X_{1}+0,196 X_{2}+0,175 X_{3}+e
$$

Penjelasan :

1. nilai konstanta (a) $=4,065$ yang menunjukkan variabel terikat bernilai $=$ 4,065 satuan.

2. Nilai koefisien $X 1$ sebesar 0,260 dan memiliki nilai koefisien positif $(+)$

3. testimoni $\left(X_{2}\right)$ didapatkan nilai $=0,196$ dan memiliki nilai koefisien positif $(+)$.

4. Variabel store atmosphere $\left(X_{3}\right)$ didapatkan nilai sebesar 0,175 dan memiliki nilai koefisien positif $(+)$.

\section{Koefisien Korelasi}

Adapun pengujian koefisen korelasi dan determinasi diperoleh hasil sebagai berikut :

Tabel 4

Interpretasi Koefisien Korelasi dan determinasi

Model Summary=

\begin{tabular}{lcccr}
\hline Model & $R$ & $\begin{array}{l}R \\
\text { Squae }\end{array}$ & $\begin{array}{l}\text { Adjusted } R \\
\text { Square }\end{array}$ & $\begin{array}{r}\text { Sts. Error of } \\
\text { the Estmate }\end{array}$ \\
\hline 1 & $776^{*}$ & .603 & 591 & 4.03177 \\
\hline Sumber: Lampran Odput SPSS
\end{tabular}

Berikut adalah interpretasi tingkat hubungan koefisien korelasi :

Tabel 5

Interpretasi Koefisien Korelasi Interval Koefisien Tingkat Hubungan Korelasi

\begin{tabular}{cc}
\hline $0,00-0,199$ & Sengat Rendah \\
$0,20-0,399$ & Rendah \\
$0,40-0,599$ & Sedang \\
$0,60-0,799$ & Kuat \\
$0,80-1,000$ & Sangat kuat \\
\hline Sumber Sugiyono $(2014: 194)$ \\
Pada pengujian didapat hasil nilai \\
koefisien korelasi $R=0,776$. Yang artinya \\
terdapat hubungan yang kuat.
\end{tabular}

\section{Koefisien Determinasi}

Hasil pengujian didapat nilai $(R-$ Square) $=0,603$. Yangartinya terdapat pengaruh sebesar $60,3 \%$..

\section{Pembuktian hipotesis}

Pembuktian Hipotesis 1 menggunakan uji-t

Tabel 6

Hasil Pengujian Hipotesis Uji-t Cosfficients:

\begin{tabular}{|c|c|c|c|}
\hline \multicolumn{2}{|c|}{ Model } & $t$ & Sig. \\
\hline \multirow{4}{*}{1} & (Constant) & 2.643 & 010 \\
\hline & Produk $\left(X_{1}\right)$ & 2.664 & .009 \\
\hline & Tesimoni $\left[x_{k}\right]$ & 2.157 & .033 \\
\hline & $\begin{array}{l}\text { Sione } \\
\text { Atmosphese }\left(\alpha_{3}\right)\end{array}$ & 2.231 & .028 \\
\hline
\end{tabular}

Berdasarkan uji yang dilakukan didapat nilai variabel produk $\left(X_{1}\right)=2,664$ dan nilai sig sebesar 0,009. Dari hasil tersebut mka hipotesis diterima.

\section{Pengujian Hipotesis 2 menggunakan uji-t}

Berdasarkan pengujian yang dilakukan didapat nilai variabel testimoni $\left(X_{2}\right)=2,157$ 
dan nilai sig $=0,033(0,033<0,05)$. maka hipotesis diterima.

\section{Pengujian hipotesis 3 menggunakan uji-t}

Berdasarkan pengujian yang dilakukan didapat nilai variabel store atmosphere $\left(X_{3}\right)=2,231$ dan nilai sig sebesar 0,028 $(0,028<0,05)$. Dari hasil tersebut maka hipotesis diterima.

\section{Penguji hipotesis 4 menggunakan uji-F}

Tabel 7

Pengujian menggunakan uji-f ANOVAN

\begin{tabular}{|c|c|c|c|c|}
\hline Mode & & $\begin{array}{l}\text { Mlean } \\
\text { Square }\end{array}$ & $F$ & sig. \\
\hline & Regession & 829.739 & 51.045 & $000=$ \\
\hline 1 & $\begin{array}{l}\text { Resious: } \\
\text { Tota: }\end{array}$ & 16.255 & & \\
\hline
\end{tabular}

Sumber: Lampian Output SPSS

Berdasarkan dari hasil pengujian yang dilakukan didapat F-hitung $=51,045$ dan nilai sig sebesar $0,000(0,000<0,05)$. maka hipotesis diterima,

\section{Pembahasan Hasil Penelitian}

Hasil pengujian hipotesis 1 dapat dinyatakan Hipotesis diterima. Yang artinya Produk berpengaruh terhadap Minat Beli Ulang di Kafe Warunk Upnormal Gresik. Produk yang baik dan berkualitas pada semua menu yang dijual akan membuat konsumen tertarik untuk melakukan pembelian ulang.

Pada pengujian hipotesis 2 didapat nilai sig $<0,05$. maka dinyatakan Hipotesis diterima. Yang artinya testimoni berpengaruh terhadap Minat Beli Ulang di Kafe Warunk Upnormal Gresik. Pengaruh testimoni terhadap minat beli ulang bernilai positif, berate setiap adanya testimoni, maka nilai minat beli ulang meningkat. Dengan adanya testimoni melalui media social yang baik akan membuat konsumen tertarik dan dapat melakukan pembelian lagi.
Pada uji hipotesis 3 didapatkan nilai sig sebesar < 0,05. maka Hipotesis diterima. Penaata warung yang rapi, nyaman dan bersih akan meningkatkan Minat Beli Ulang konsumen di Kafe Warunk Upnormal Gresik. Warung upnormal mendesain tempat usahannya dengan baik dan membuat konsumen betah ketika melakukan pembelian.

Pengujian hipotesis 4 didapat nilai sig < 0,05. Uji secara bersama-sama dilakukan untuk mengetahui Pengaruh Produk, Testimoni dan Store Atmosphere secara simultan, dengan adanya produk yang berkualitas yang ditunjang oleh testimony produk dan disuport dengan penataan tempat usaha yang nyaman, maka konsumen akan tertarik untuk kembali melakukan pembelian.

\section{Simpulan}

1. Produk secara parsial berpengaruh positif dan signifikan terhadap Minat Beli Ulang di Kafe Warunk Upnormal Gresik

2. Terdapat pengaruh Testimoni terhadap Minat Beli Ulang di Kafe Warunk Upnormal Gresik..

3. Terdapat pengaruh Store Atmosphere terhadap Minat Beli Ulang di Kafe Warunk Upnormal Gresik..

4. secara simultan ketiga variabel berpengaruh positif dan signifikan terhadap Minat Beli Ulang di Kafe Warunk Upnormal Gresik..

\section{Implikasi}

Implikasi yang didapat dari penelitian ini adalah peningkatan kualitas produk yang dijual termasuk bahan baku dari produlk yang akan dijual harus berkualitas, disamping itu penntingnya testimony dari pelanggan yang telah melakukan pembelian serata penataan tempat pakan pada warunk up normal. Dari ketiga impikasi tersebut akan 
membuat warunk up normal semalkin berkjembang

\section{Keterbatasan Penelitian}

Peneliti mengalami keterbatasan dalam pengambilan kuisioner dikarenakan banyak faktor yang tidak boleh diketahui peneliti dan hanya faktorfaktor tertentu saja.

\section{Daftar Rujukan}

Philip Kotler , 2014, Manajemen Pemasaran, Jakarta : Erlangga Jilid 2.

Ratnasari Tri Ririn, Mastuti H Aksa. 2016. Manajemen Pemasaran Jasa. Penerbit: Ghalia Indonesia

Sugiyono. 2015. Metode Penelitian Administrasi. Bandung: Alfabeta.

Sukmawati, P dan Durianto. 2014. Manajemen Pemasaran. Jakarta : Erlangga 